\title{
Apoptosis to necrosis switching downstream of apoptosome formation requires inhibition of both glycolysis and oxidative phosphorylation in a $B C L-X_{L}-$ and $P K B / A K T$-independent fashion
}

\author{
D Gramaglia ${ }^{1}$, A Gentile ${ }^{1}$, M Battaglia ${ }^{1}$, L Ranzato ${ }^{2}$, \\ V Petronilli ${ }^{2,3}$, M Fassetta ${ }^{1}$, P Bernardi ${ }^{2,3}$ and A Rasola ${ }^{*, 1}$ \\ 1 Division of Molecular Oncology, Institute for Cancer Research, University of \\ Torino Medical School, Candiolo, Italy \\ 2 Venetian Institute of Molecular Medicine, University of Padova, Italy \\ ${ }^{3}$ CNR Institute of Neurosciences at the Department of Biomedical Sciences, \\ University of Padova, Italy \\ * Corresponding author: A Rasola, IRCC, Institute for Cancer Research, \\ University of Torino Medical School, Strada Provinciale 142, Km 3.95, \\ Candiolo (TO) 10060, Italy. Tel: + 39011 9933210; Fax: + 39011 9933225; \\ E-mail: andrea.rasola@ircc.it
}

Received 18.4.03; revised 01.8.03; accepted 08.8.03; published online 09.1.04 Edited by RA Knight

\begin{abstract}
Human T-lymphoma Jurkat cells treated with several intrinsic death stimuli readily undergo a stepwise apoptotic program. Treatment with 1,9-dideoxyforskolin (ddFSK), an inactive analogue of the adenylate cyclase activator forskolin, induces necrotic cell death and switches to necrosis the response to the apoptosis inducers in Jurkat and in other cell models. Yet, in the presence of ddFSK, mitochondrial changes are enhanced and apoptosome formation takes place. We show that ddFSK does not inhibit the catabolic steps of apoptosis, but rather elicits a profound ATP depletion that in turn tunes the mode of cell demise towards necrosis. Treatment with ddFSK impairs both glycolysis and oxidative phosphorylation in a Bcl- $\mathrm{X}_{\mathrm{L}}$ - and PKB/Akt-independent fashion, and inhibition of both processes is needed to affect apoptosis progression. Apoptosis is not blocked per se by ATP depletion, as engagement of the Fas receptor directly activates caspases, thus bypassing ddFSK inhibition.

Cell Death and Differentiation (2004) 11, 342-353. doi:10.1038/ sj.cdd. 4401326

Published online 9 January 2004
\end{abstract}

Keywords: apoptosis; necrosis; PKB/Akt; Bcl- $\mathrm{X}_{\mathrm{L}}$; 1,9-dideoxyforskolin; energy metabolism

Abbreviations: AIF, apoptosis-inducing factor; Anis, anisomycin; ANT, antimycin A; CCCP, carbonil cyanide m-chlorophenylhydrazone; CPT, camptothecin; cyt $c$, cytochrome c; DAPI, 4',6diamidino-2-phenylindole; ddFSK, 1,9-dideoxyforskolin; 2DG, 2deoxyglucose; $\Delta \psi_{\mathrm{m}}$, mitochondrial electrochemical gradient; ETO, etoposide; FCCP, carbonyl cyanide 4-trifluoromethoxyphenyl-hydrazone; GSK3, glycerol synthase kinase 3; MAN, mannitol; PARP, poly (ADP-ribose) polymerase; PCD, programmed cell death; $\mathrm{PI}$, propidium iodide; $\mathrm{ROT}$, rotenone; Smac/DIABLO, second mitochondrial-released activator of caspases/direct IAPbinding protein with a low isoelectric point; STS, staurosporine; TMRM, tetramethylrhodamine methyl ester; 5TG, 5-thyoglucose; TUNEL, TdT-mediated dUTP-X nick end labeling

\section{Introduction}

Programmed cell death (PCD) is endowed with a highly stereotypical series of morphological and biochemical changes. The PCD process is defined as apoptosis when these features include the activation of proteases termed caspases, cytoplasmic shrinkage, loss of plasma membrane lipid asymmetry, chromatin condensation and DNA degradation into oligonucleosomal fragments. ${ }^{1,2}$

Apoptosis can be initiated by the engagement of the plasma membrane death receptors (extrinsic pathway), or by changes in the mitochondrial integrity following either a broad range of physical and chemical stimuli or growth factor withdrawal (intrinsic pathway ${ }^{3}$ ). Pro- and antiapoptotic members of the Bcl-2 family of proteins integrate intrinsic signals, leading either to cell survival by maintaining mitochondrial homeostasis, or to cell death by releasing in the cytosol apoptogenic proteins stored in the mitochondria. ${ }^{4}$ These molecules contribute to the formation of the apoptosome, a multimolecular complex that triggers caspase activation, a mandatory event for cell dismantling through the intrinsic pathway. ${ }^{5}$ On the other hand, when apoptosis is elicited by the extrinsic pathway, the caspase cascade can rely upon the aforementioned stages, or alternatively it can be directly activated following death receptor engagement, thus skipping mitochondria requirement. ${ }^{6}$

Execution of the cell death program displays a remarkable plasticity. Indeed, the modes of cell demise comprise a number of processes spanning the entire range of intermediate options between apoptosis and necrosis, including apoptosis-like PCD and necrosis-like PCD. ${ }^{7}$ In necrotic cells, the cytosol and the organelles rapidly swell and the nuclear structure and DNA are degraded in a nonspecific fashion. ${ }^{2}$ The different forms of PCD comprised between the extremes of apoptosis and necrosis are mostly endowed with a lack of caspase activation and with any degree or combination of other apoptotic-like hallmarks. The choice among these different forms of cell death is determined by complex factors. In some cases, a normal apoptosis program is interrupted and the PCD is terminated by caspase-independent routes. ${ }^{8}$ Caspase pathways can be silenced by an array of factors, such as inhibitory peptide or proteins, ${ }^{9}$ nitrative/oxidative 
stress, ${ }^{10}$ or energy depletion, ${ }^{11}$ and, in turn, the cell can switch from an apoptotic to a necrotic-like death process. ${ }^{7}$

Prevention of ATP production was shown to inhibit caspase activation in some experimental models, ${ }^{12-14}$ and the molecules that couple apoptosis regulation and energy metabolism are currently under investigation. The Bcl-2 family protein $\mathrm{Bcl}-\mathrm{X}_{\mathrm{L}}$ was reported to prevent cell death by maintaining oxidative phosphorylation even in conditions of metabolite deprivation. ${ }^{15-17}$ The $\mathrm{PKB} / \mathrm{Akt}$ serine/threonine kinase increases glucose uptake and glycolytic activity, ${ }^{18-20}$ and thus stimulates cell metabolism by enhancing substrate availability for mitochondrial activity. ${ }^{21,22}$

In this study, we provide evidence that treatment of Tlymphoma cells and other cell models with several intrinsic apoptotic agents results in a PCD program aborted downstream of apoptosome formation when cells are exposed to 1,9-dideoxyforskolin (ddFSK), a diterpenoid often used as a negative control of the adenylyl cyclase activator forskolin. On the contrary, the response mediated by death receptor engagement is not affected or slightly increased by ddFSK. We report that ddFSK causes massive energy depletion and mitochondrial functional impairment in a Bcl- $\mathrm{X}_{\mathrm{L}}$ - and PKB/Aktindependent way. This metabolic arrest involves both glycolysis and oxidative phosphorylation, thus indicating that the inhibition of both processes is required to switch the mode of cell demise after apoptosome formation.

\section{Results}

\section{Apoptosis induction through the intrinsic pathway is switched to necrosis by cell treatment with 1,9- dideoxyforskolin}

Human T-leukemia Jurkat cells were exposed to different apoptosis inducers: staurosporine (STS), a wide-range protein kinase inhibitor; anisomycin (Anis), a Jun kinase activator and protein synthesis inhibitor; camptothecin (CPT) or etoposide (ETO), inhibitors of DNA topoisomerase I and II, respectively; mannitol (MAN), which elicits a hyperosmotic shock; and the anti-Fas agonist antibody $\mathrm{CH} 11$. This latter compound triggers an extrinsic apoptotic pathway by eliciting the trimerization of the Fas receptor, whereas all other agents activate an intrinsic, receptor-independent apoptotic process.

By using a cytofluorimetric technique set up in our group, ${ }^{23}$ we simultaneously investigated different apoptotic features: cell shrinkage and increase in granularity (light-scatter parameters); decrease in the mitochondrial membrane potential $\left(\Delta \psi_{\mathrm{m}}\right.$, measured as reduced staining with the probe TMRM); exposure of phosphatidylserine (PS) on the cell surface (Annexin V-FITC staining) and permeabilization of the plasma membrane to propidium iodide (PI), that is, cell death. Jurkat cells treated with STS, Anis, CPT, ETO, MAN or anti-Fas entered the apoptosis program, as assessed by a decrease of $\Delta \psi_{\mathrm{m}}$ and PS flipping across the plasma membrane. The wide-range caspase inhibitor Z.VAD-fmk abolished or reduced all apoptotic changes (Figure 1a, b and not shown).

We had observed that ddFSK, an inactive analogue of the adenylyl cyclase activator forskolin, interfered with some late apoptotic degradation events. ${ }^{24}$ In our experimental conditions, a short-term $(5 \mathrm{~h})$ cell exposure to ddFSK caused a marked mitochondrial depolarization and a moderate increase of the fraction of cells displaying PS exposure and PI permeability, independently of caspase activity (Figure 1a, b). Remarkably, this pattern of cell response was not changed when ddFSK was supplied together with the intrinsic apoptotic inducers, thus suggesting that the apoptotic response to these compounds was abrogated by ddFSK (Figure 1a, b). Instead, the coincubation of Jurkat cells with the anti-Fas antibody and ddFSK increased all apoptotic parameters in a caspasedependent fashion (Figure 1a). This effect of ddFSK on apoptosis induction was not restricted to Jurkat cells, as it was observed also in the lymphoblastic leukemia CEM cells (Figure 1c), in the monocytic THP-1 cells and in the colon carcinoma COLO741 cells (data not shown). As depicted in Figure 1d, a longer ( $8 \mathrm{~h}$ ) cell exposure to ddFSK, alone or in combination with the proapoptotic compounds, induced cytosolic shrinkage and increase of cell granularity. Shrunken and granular cells were also PI-permeable, indicating that they were either in late apoptotic stages or undergoing necrosis. Moreover, ddFSK inhibited nuclear apoptotic changes caused by the intrinsic apoptosis inducers (such as nuclear fragmentation and appearance of cells with hypodiploid DNA), whereas it increased the percentage of cells undergoing these apoptotic changes after Fas engagement (Figure 1e,f).

Collectively, these data indicate that ddFSK by itself causes necrosis, while it induces an apoptosis-to-necrosis switch when cells are challenged with an intrinsic apoptotic stimulus.

\section{Release of apoptogenic proteins from mitochondria is increased by ddFSK}

The release of several apoptogenic molecules from the mitochondria, such as cyt $c$, AIF and SMAC/Diablo, is crucial for the activation of the degradation machinery in most apoptotic pathways. ${ }^{5}$

As depicted in the cell fractionation experiments of Figure $2 \mathrm{a}-\mathrm{c}$, cell treatment with STS, Anis, or with the $\mathrm{CH} 11$ anti-Fas antibody caused the release into the cytosol of cyt $c$, SMAC/ Diablo and AIF. Figure $2 \mathrm{~d}$ also shows the effect of Anis on the release of procaspase-3. All these proteins were also shed from the membrane and organelle fraction of cells treated with ddFSK, and the coincubation of ddFSK with the proapoptotic agonists further enhanced this release (Figure $2 a-d$ ). We verified that these results faithfully represented the cell status prior to cell disruption. An in situ immunofluorescence experiment (Figure 2e) shows that the signals of an anticytochrome oxidase subunit VIc and of an anti-cyt $c$ antibody only colocalized in untreated Jurkat cells, as revealed by the yellow color of the overlay in the control panels, whereas a diffuse red fluorescence could be detected in the overlay images after treatment with anisomycin and ddFSK alone or in combination. Similar results were obtained by replacing the anti-cyt $c$ with an anti-SMAC/Diablo or with an anti-AIF antibody (not shown).

\section{Caspase activity, but not formation of the apoptosome, is impaired by ddFSK}

Caspase activation downstream of mitochondria requires the formation of the multimolecular apoptosome, whose main 
a

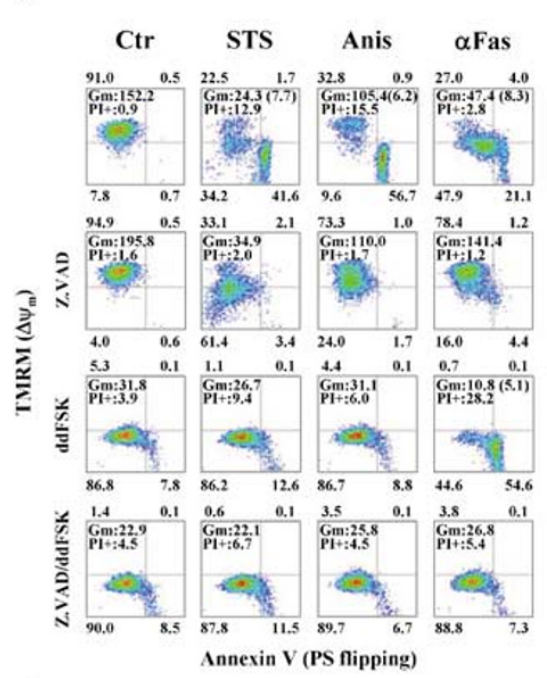

d
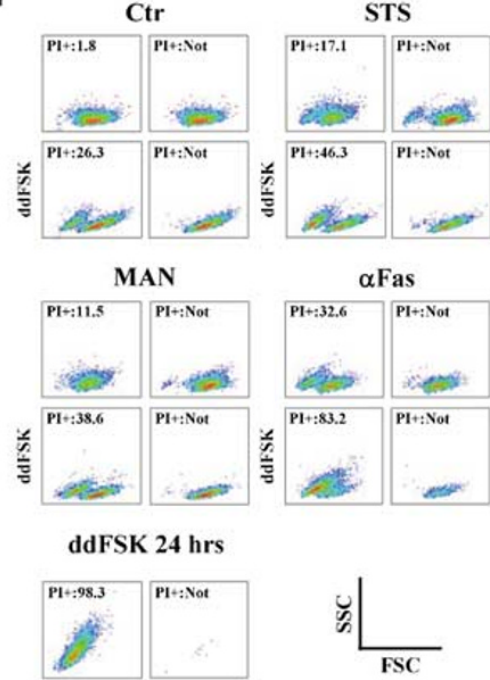

$\alpha$ Fas
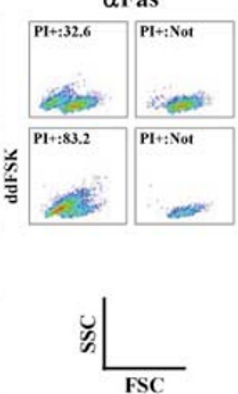
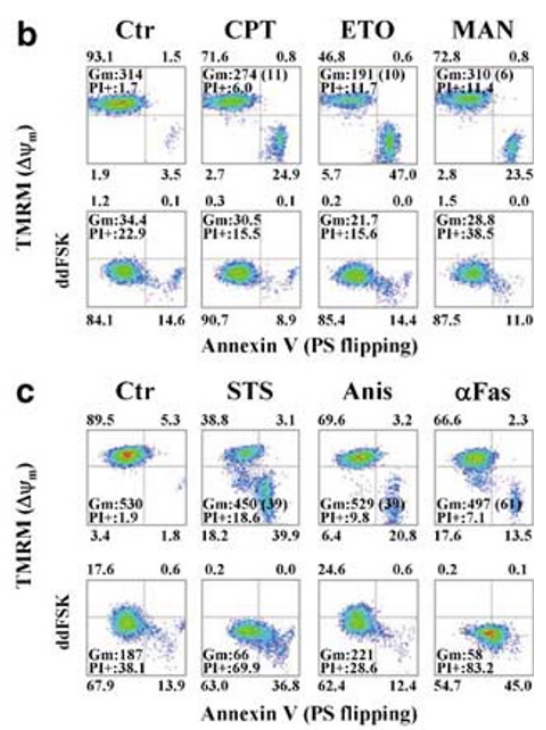

e

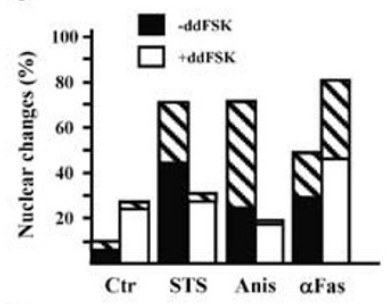

f

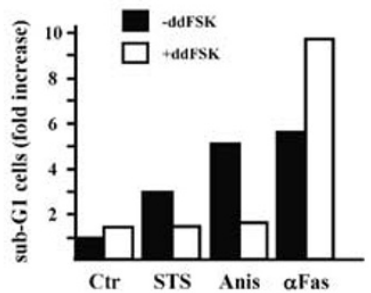

Figure 1 Effect of ddFSK on apoptosis induction. (a, b) Jurkat cells were exposed for $5 \mathrm{~h}$ to $150 \mathrm{ng} / \mathrm{ml} \mathrm{STS}, 500 \mathrm{ng} / \mathrm{ml}$ anisomycin (Anis), $150 \mathrm{ng} / \mathrm{ml} \mathrm{CH} 11 \mathrm{anti}-\mathrm{Fas}$ antibody ( $\alpha$ Fas), $1 \mu \mathrm{M}$ camptothecin (CPT), $100 \mu \mathrm{M}$ etoposide (ETO), or to a 500 mosM hyperosmotic shock obtained by adding mannitol (MAN) to the medium. Where indicated, cells were pretreated for 30 min with the caspase inhibitor Z.VAD-fmk (Z.VAD; $100 \mu \mathrm{M})$, and/or for 5 min with ddFSK (200 $\mu \mathrm{M})$. Diagrams represent Annexin VFITC versus TMRM staining; the percentages of the cell populations in each quadrant are indicated. Cells displaying a decrease of $\Delta \psi_{\mathrm{m}}$ are in the lower parts of each plot, whereas cells exposing PS on their surface are in the right quarters of the diagrams. The geometric mean $(\mathrm{Gm})$ values of the staining with TMRM are a quantitative measurement of mitochondrial depolarization, calculated on the whole-cell population; in parentheses are reported the Gm values of the apoptotic cells. PI + is the percentage of propidium iodide-permeable cells. In (c), the same experiment of (a) was performed on CEM cells. (d) Forward scatter (FSC) vs side scatter (SSC) analysis of Jurkat cells. Treatment with $200 \mu \mathrm{M}$ ddFSK for $8 \mathrm{~h}$ caused cell shrinkage (reduction of the FSC parameter) and enhancement of cell granularity (increase of the SSC parameter). This cell subpopulation was also endowed with PI permeability, as shown by excluding PI + cells (PI + :Not) on the same analysis. (e) Nuclear changes were measured by DAPI staining on Jurkat cells treated in the same conditions of (a). Bars represent the percentage of cells displaying chromatin condensation (filled or white bars) and nuclear fragmentation (hatched bars). (f) Flow cytometry analysis of hypodiploid cells (sub-G1 population) on Jurkat cells treated in the same conditions of (a)

constituents are Apaf-1, procaspase- 9 and cyt $c$. The apoptosome further induces the recruitment of caspase-3 and catalyzes caspase cleavage. ${ }^{5}$ The immunoprecipitation experiment of Figure $3 a$ documents that the aggregation of Apaf-1, caspase- 9 and caspase- 3 was not prevented by ddFSK after treatment with the different apoptotic stimuli. Cell treatment with STS, Anis and anti-Fas agonist antibody caused cleavage of the zymogenic forms of caspase-3 (Figure 3a), caspase-7 (Figure 3b), caspase-8 (Figure 3d) and caspase-9 (Figure 3f). However, when ddFSK was provided together with STS and Anis, the activating cleavage of these caspases was prevented. In contrast, the coadministration of anti-Fas and ddFSK did not block or even augmented the extent of caspase proteolysis. In perfect keeping with its effects on cleavage, ddFSK markedly inhibited the activity of this pool of caspases when apoptosis was triggered by STS or Anis, but was completely ineffective following the engagement of the Fas receptor (Figure 3c, e and $\mathrm{g}$ ).

Likewise, the cleavage of lamin B, a substrate of caspase- 6 , and of PARP, a substrate of caspase-3-like enzymes, to the expected fragments were prevented by ddFSK when apoptosis was elicited by STS and Anis, but not when the $\mathrm{CH} 11$ 
a

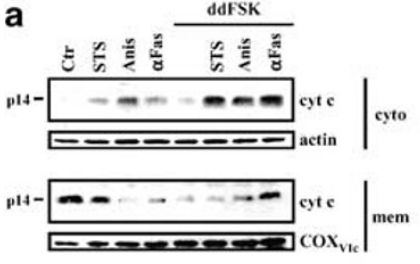

b
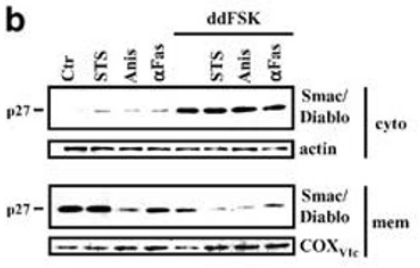

c

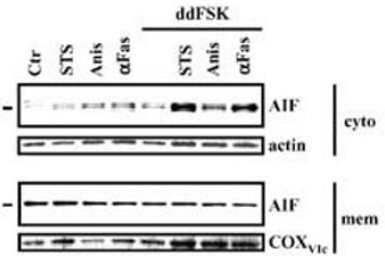

d

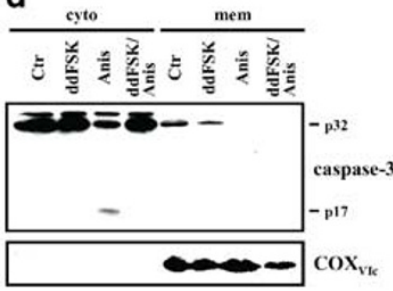

e

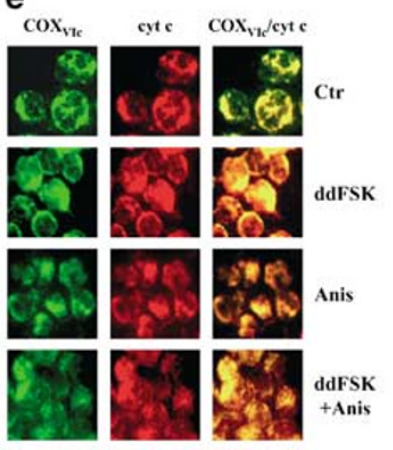

Figure 2 Effect of ddFSK on the release of mitochondrial apoptogenic proteins. Jurkat cells were incubated in the same conditions of Figure 1. Western immunoblot detection of cyt $c$ (a), Smac/Diablo (b), AIF (c) and caspase-3 (d) was performed either on the cytosolic (cyto) or on the membrane (mem) cell fractions. The same blots were rehybridized with an antiactin antibody to verify the protein loading, or with an anti-cytochrome oxidase VIc antibody $\left(\mathrm{COX}_{\mathrm{VIC}}\right)$ to demonstrate the presence of mitochondria in the membrane fractions. The immunofluorescence in (e) reports the staining of cells with the anti-COX conjugated to fluorescein isothiocyanate and with the anti-cyt $c$ conjugated to phycoerythrin. As shown by the fluorescence superimposition, a $5 \mathrm{~h}$ cell treatment with ddFSK $(200 \mu \mathrm{M})$ and/or Anis caused release of cyt $c$ from the mitochondria

anti-Fas antibody was the death stimulus (Figure 4a). ddFSK largely prevented DNA fragmentation induced by STS or Anis, irrespective of whether an agarose gel assay or a TUNEL approach was used for detection (Figure $4 \mathrm{~b}, \mathrm{c}$, respectively). However, ddFSK increased the DNA cleavage induced by Fas as measured by the TUNEL assay but not by the agarose gel approach, suggesting a negative regulation of the DFF45/ CAD nuclease responsible for the nucleosomal fragmentation. We also incubated Jurkat cell lysates in vitro with dATP and cyt $c$. As reported in Figure $5 \mathrm{a}$, cell lysate incubation with ddFSK did not affect either caspase-9/caspase-3 activation or PARP cleavage. In the presence of ddFSK, cell lysates pretreated with all the proapoptotic compounds maintained their ability to cleave an added DNA that retains its nucleosomal structure (Figure $5 b$ ).

Thus, ddFSK interrupts the intrinsic apoptotic pathways by inhibiting caspases downstream of the formation of the apoptosome, and it does not block apoptosome activation, caspase activity or DNA cleavage through a direct mechanism.

\section{ddFSK has limited effects on mitochondrial function}

We then asked whether ddFSK directly affects mitochondrial function. In isolated mitochondria, ddFSK induced a delayed and modest depolarization that remained stable over several

minutes (Figure 6a), but it did not cause cyt $c$ release (data not shown). Furthermore, ddFSK inhibited the respiratory rate of isolated mitochondria, and this effect could be better appreciated when the electron flux was maximally stimulated by the addition of a protonophoric uncoupler; this inhibition of respiration was matched by a depolarization of $10-20 \mathrm{mV}$ (Table 1). These data suggest that ddFSK may depolarize mitochondria as a consequence of its inhibition of respiration.

To investigate this possibility, $\Delta \psi_{\mathrm{m}}$ was studied in Jurkat cells with the cytofluorimetric approach reported above. ddFSK-mediated mitochondrial depolarization was a slow process: only after a $5 \mathrm{~h}$ exposure, all cells displayed depolarized mitochondria, and after $24 \mathrm{~h}$ no viable cells were detectable, further indicating cell necrosis (Figure 6b). A dose-response analysis indicated that up to $100 \mu \mathrm{M}$ ddFSK was ineffective at triggering mitochondrial depolarization, whereas it was abruptly elicited by $200 \mu \mathrm{M}$ ddFSK (Figure 6b).

Strikingly, ddFSK markedly enhanced the mitochondrial depolarization and the plasma membrane permeability to $\mathrm{PI}$ caused by antimycin A (ANT) or rotenone (ROT), which, respectively, inhibit complex III and I of the respiratory chain, and of the protonophore carbonil cyanide m-chlorophenylhydrazone (CCCP; Figure 7a). In all cases, ddFSK acted in a caspase-independent fashion (not shown). ddFSK increased the rate of depolarization induced by ANT, at the early time points (Figure 7b), and the association of ddFSK and ANT was highly lethal to cells, as about half of them were dead after $2 \mathrm{~h}$ (not shown). ddFSK was also tested in association with some modulators of the mitochondrial permeability transition pore (PTP), which may be implicated in mitochondrial depolarization and release of apoptogenic proteins. The two PTP inducers PK11195 (a ligand of the peripheral benzodiazepine receptor) and the thiol oxidant diamide were ineffective perse, but increased the rate of mitochondrial depolarization and of cell death induced by ddFSK (not shown). Other modulators of the PTP, such as the ROS scavenger $\mathrm{N}$-acetyl-cysteine, the voltage-dependent anion channel (VDAC) modulators Koenig's polyanion or dextran sulphate, were ineffective (not shown).

Jurkat cells were then exposed to the apoptotic inducers with or without ANT. Even though in all experimental conditions ANT caused a marked $\Delta \psi_{\mathrm{m}}$ decrease (Figure 7c), caspase activity was never impaired, as shown by the cleavage of PARP and by nucleosomal DNA fragmentation (Figure 7d,e).

Taken together, these data indicate that mitochondrial depolarization is not sufficient per se to inhibit downstream apoptotic events, and that the ddFSK-dependent mitochondrial changes are additive with those caused by a bona fide protonophore, by respiratory inhibitors and by some PTP inhibitors. This suggests that the effects of ddFSK on the mode of cell death may not be due to its direct, modest effects on mitochondrial energy conservation.

\section{Energy metabolism is dramatically changed by ddFSK}

Cell exposure to ddFSK caused a dramatic depletion of intracellular ATP. The effect of ddFSK was dose-dependent 

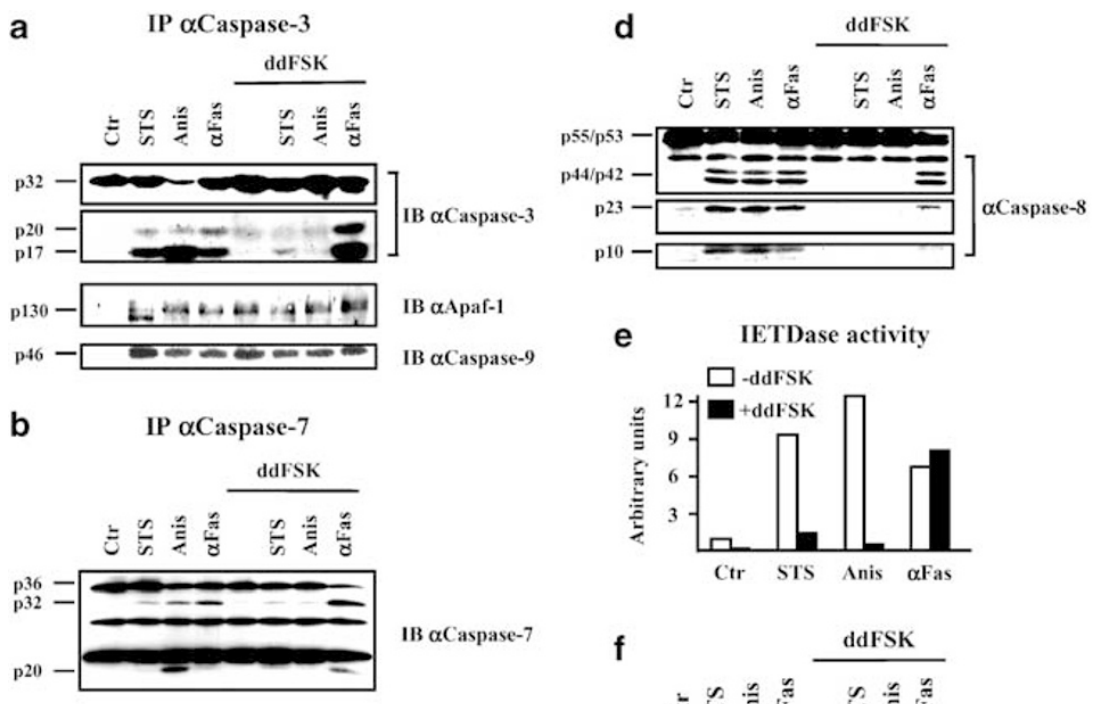

e IETDase activity

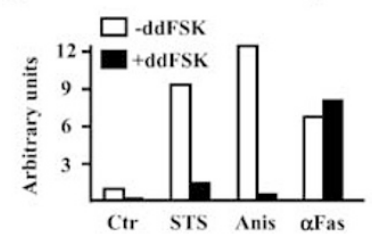

C DEVDase activity
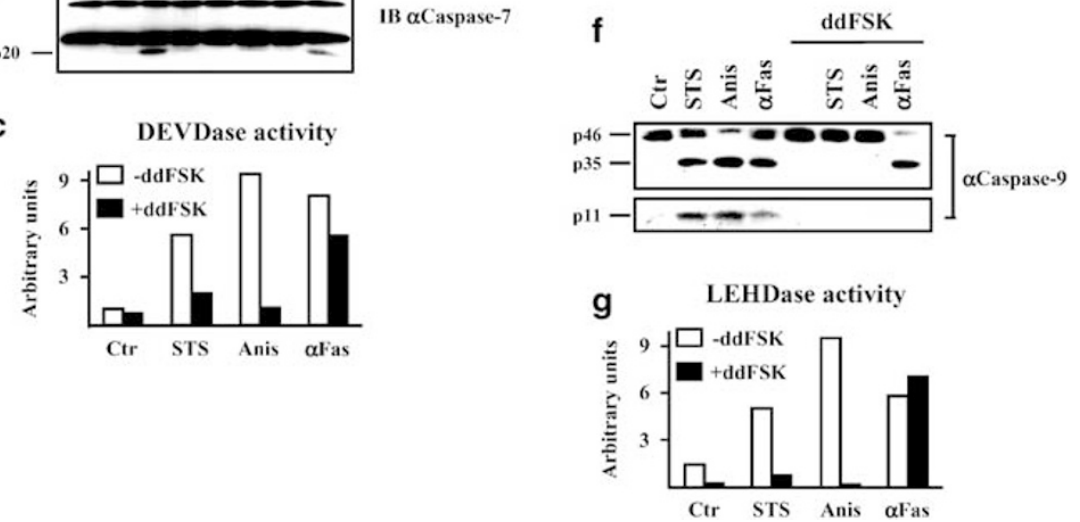

Figure 3 Effect of ddFSK on the activation of caspases. Jurkat cells were incubated in the same conditions as in Figure 1. In (a), caspase-3 was immunoprecipitated and the blot was probed with an antibody recognizing both its p32 zymogenic form and its p20/p17 active fragments, with an anti-Apaf-1 antibody and with an anticaspase-9. In (b), (d), (f), the activation of caspase-7, caspase-8 and caspase-9, respectively, was detected as cleavage of the zymogenic forms of the enzymes. In (c), (e), (g), caspase activity was measured as cleavage of the chromophore-conjugated substrates of caspase-3/7 DEVD-pNA (DEVDase activity), caspase-8 IETD-pNA (IETDase activity) or caspase-9 LEHD-pNA (LEHDase activity). Values are reported as arbitrary colorimetric units normalized versus control conditions

(Figure $8 \mathrm{a}$ ), and it was almost maximal after $2 \mathrm{~h}$ of incubation. After $5 \mathrm{~h}$, the intracellular concentration of ATP was nearly reduced to background levels (Figure $8 b$ ). This massive ATP depletion took place irrespective of any apoptosis induction, and it was much higher than that obtained with oligomycin or ANT (Figure 8c), which block oxidative phosphorylation by inhibiting the mitochondrial ATP synthase and the respiratory chain, respectively.

In principle, the ATP-depleting effect of ddFSK could be due to an enhancement of ATP hydrolysis by one or more cellular ATPases. However, cell treatment with several ATPase inhibitors (ouabain for $\mathrm{Na}^{+} / \mathrm{K}^{+}$-ATPase, oligomycin for the mitochondrial $F_{0} F_{1}$ ATPase, Na-orthovanadate for cytosolic $\mathrm{Ca}^{2+}$-ATPases, thapsigargin for microsomal $\mathrm{Ca}^{2+}$-ATPases and bafilomycin $\mathrm{A}_{1}$ for vacuolar-type $\mathrm{H}^{+}$ATPases) did not alter the effect of ddFSK. Interestingly, inhibition of the $F_{0} F_{1}$ ATPase caused an acceleration of the ddFSK-dependent ATP consumption, indicating a synergistic effect between ddFSK and oligomycin (Figure 8d). As reported in Figure 8e, even when cells were placed in a glucose-free medium, that is, in conditions of no glycolysis, the depletion effect of ddFSK did not change at all. The absence of any glycolytic-mediated ATP production was verified by inhibiting oxidative phosphorylation with oligomycin or ANT. These results show that depletion of ATP induced by ddFSK cannot be counteracted by ATP synthesis by mitochondria or by glycolysis.

To verify whether ddFSK could have a direct effect on glycolytic activity, we assessed its effect on lactate production. As depicted in Figure $8 \mathrm{f}, \mathrm{g}$, ddFSK rapidly arrested lactate production, and the effect was similar to that observed with the hexokinase inhibitors 2-deoxy-glucose (2DG) and 5thio-glucose (5TG). Lactate production in the presence of ddFSK was comparable to that of cells kept in medium without glucose. A direct interaction of ddFSK with lactate dehydrogenase was excluded by experiments performed in the presence of pyruvate, whereas a colorimetric assay performed with purified hexokinase showed no direct effect of the drug on this enzyme (not shown). ddFSK also completely impaired glucose consumption from the culture medium, similarly to the hexokinase blockers. Remarkably, both ddFSK and 5TG elicited glucose release when cells were incubated in glucose-free medium (Figure $8 \mathrm{~h}$ ), suggesting that glycolysis inhibition triggers a feedback loop that outwardly activates the membrane transporter. It must be pointed out that neither 2DG nor 5TG induce any mitochondrial depolarization, whereas the effect on ATP depletion was lower than that of ddFSK and additive to it (not shown). Thus, the inhibitory effects on cell energy metabolism caused by 
a

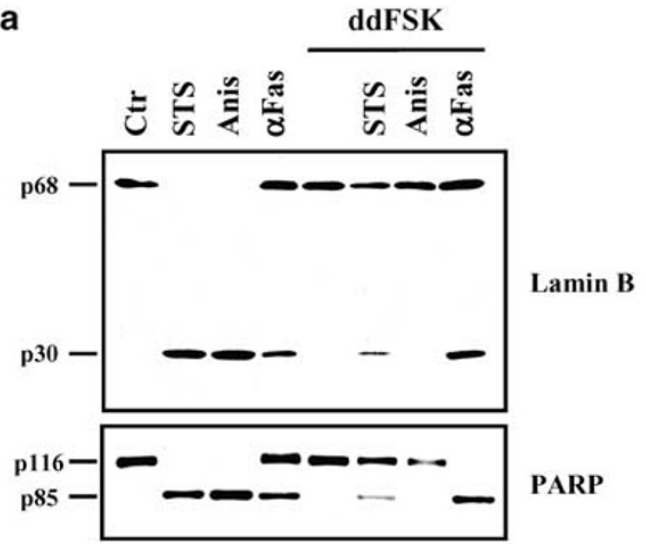

b

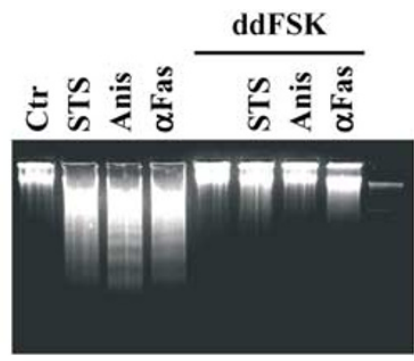

c
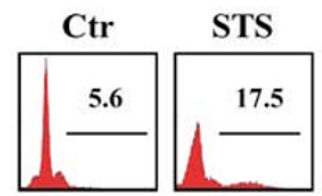

Anis
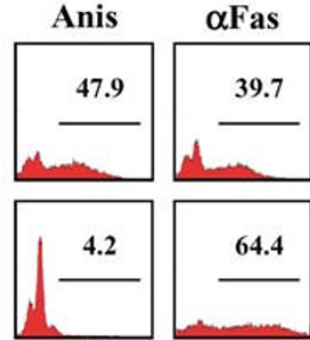

Figure 4 Effect of ddFSK on the cleavage of caspase targets and on DNA fragmentation. Jurkat cells were incubated in the same conditions of Figure 1. In (a), Western immunoblot assessment of the cleavage of lamin B and of PARP. In (b), DNA fragmentation was detected by agarose gel electrophoresis, whereas in (c) it was investigated with the cytofluorimetric TUNEL technique. These latter data are presented as fluorescence intensity on a logarithmic scale versus the number of recorded events. The peak on the left represents cells with intact DNA, that on the right apoptotic cells, whose percentage is reported above the horizontal line

ddFSK are additive to those obtained blocking either oxidative phosphorylation or glycolysis.

\section{Bcl- $\mathrm{X}_{\mathrm{L}}$ or PKB/Akt overexpression do not change the effects of ddFSK}

The antiapoptotic protein $\mathrm{Bcl}-\mathrm{X}_{\mathrm{L}}$ prevents mitochondrial dysfunction and cyt $c$ release in several models of apoptosis induction (e.g. Vander Heiden et al. ${ }^{17}$ ). To investigate whether $\mathrm{Bcl}-\mathrm{X}_{\mathrm{L}}$ could reverse the effects on apoptosis and energy metabolism mediated by ddFSK, we stably overexpressed $\mathrm{Bcl}-\mathrm{X}_{\mathrm{L}}$ in Jurkat cells. As depicted in Figure $9 \mathrm{a}, \mathrm{Bcl}-\mathrm{X}_{\mathrm{L}}$ overexpression did not inhibit the profound ATP depletion caused by ddFSK, either in basal or in apoptotic conditions. Moreover, even though $\mathrm{Bcl}-\mathrm{X}_{\mathrm{L}}$-transfected cells treated with apoptosis inducers had a reduced caspase activity as

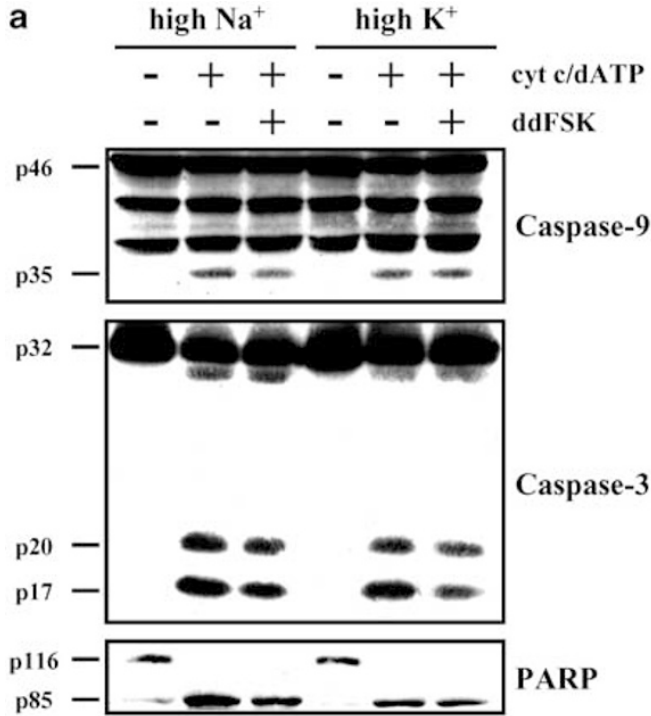

b

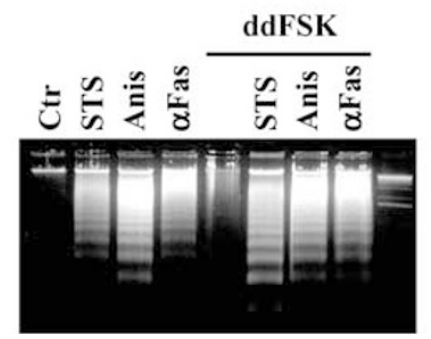

Figure 5 In vitro regulation of caspase activity. (a) Western immunoblot analysis of the cleavage of caspase-9, caspase- 3 and PARP after a $2 \mathrm{~h}$ in vitro incubation of Jurkat cell lysates with $10 \mu \mathrm{M}$ cyt $c$ and $1 \mathrm{mM}$ dATP. The addition of $200 \mu \mathrm{M}$ ddFSK to the incubation mixture did not alter the cleavage pattern. To exclude for nonspecific effects of the medium on caspase activity, experiments were performed in a buffer containing either $30 \mathrm{mM} \mathrm{Na}^{+}$or $30 \mathrm{mM} \mathrm{K}^{+}$as the main cation. (b) In vitro oligonucleosomal fragmentation of high molecular weight calf thymus DNA after a $2 \mathrm{~h}$ incubation with cytosolic extracts of Jurkat cells preexposed for $4 \mathrm{~h}$ to $150 \mathrm{ng} / \mathrm{ml} \mathrm{STS}, 500 \mathrm{ng} / \mathrm{ml}$ Anis or $150 \mathrm{ng} / \mathrm{ml} \alpha$ Fas. Where indicated, $200 \mu \mathrm{M}$ ddFSK was added to the DNA incubation mixture

compared to wild-type Jurkat cells (compare Figures 9b and $3 c$ ), this activity was further blocked by ddFSK. Remarkably, the $\Delta \psi_{\mathrm{m}}$ decrease caused by our apoptotic agonists was markedly reduced by $\mathrm{Bcl}-\mathrm{X}_{\mathrm{L}}$ overexpression, but the ddFSKdependent mitochondrial depolarization was not affected, irrespective of apoptosis induction (Figure 9c). Therefore, neither the loss of $\Delta \psi_{\mathrm{m}}$ nor the intracellular ATP depletion caused by ddFSK can be inhibited by the antiapoptotic activity of $\mathrm{Bcl}-\mathrm{X}_{\mathrm{L}}$.

The PKB/Akt serine/threonine kinase is a major effector of cell survival, and its capability to increase glucose metabolism $^{22}$ allows maintenance of glycolysis and a better supply of respiratory substrates to mitochondria, which might preserve mitochondrial integrity and function. ${ }^{21}$ The hallmark of PKB/ Akt activation is the phosphorylation at the Thr308/Ser473 residues. As reported in Figure 10a, the phosphorylation of Ser473-Akt was abolished by ddFSK treatment independently of apoptosis induction. The kinetics and dose response of PKB/Akt phosphorylation after the addition of ddFSK were strikingly similar to those displayed by mitochondrial depolarization and ATP depletion (compare Figure 10b, c with 


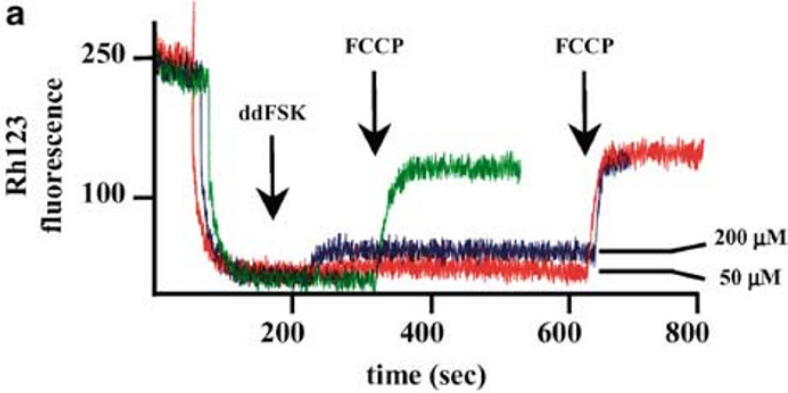

b Ctr

ddFSK/5hrs

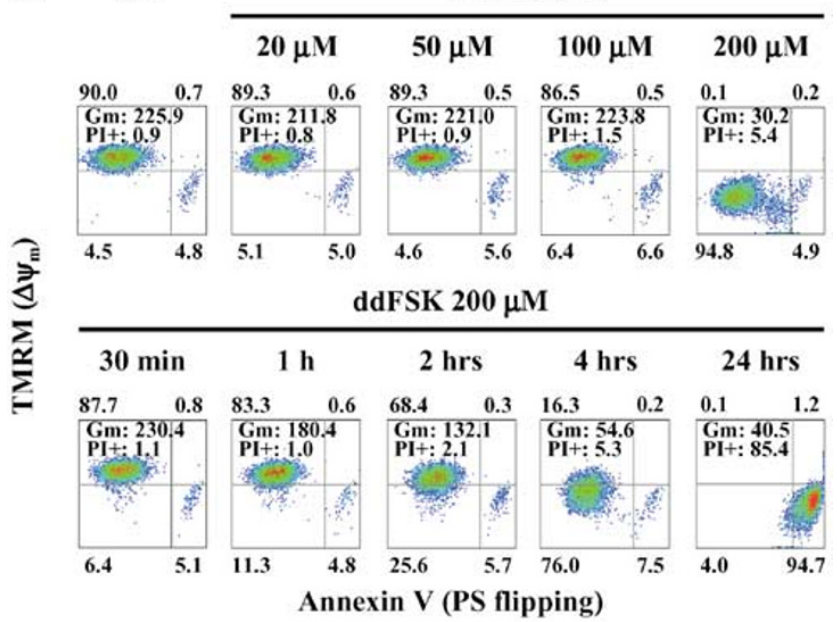

Figure 6 Effect of ddFSK on mitochondrial polarization. In (a), $\Delta \psi_{\mathrm{m}}$ was studied on isolated organelles with the fluorescent probe rhodamine 123. Traces represent mitochondria in control conditions (green) or treated with ddFSK (50 $\mu \mathrm{M}$, red; $200 \mu \mathrm{M}$, blue); at the end of each experiment, mitochondria were completely depolarized with the proton uncoupler carbonyl cyanide $p$ trifluoromethoxyphenyl-hydrazone (FCCP). In (b), dose-response and kinetic analysis of ddFSK-mediated $\Delta \psi_{\mathrm{m}}$ breakdown and PS exposure. In the upper row, Jurkat cells were exposed for $5 \mathrm{~h}$ to ddFSK at the reported concentrations. In the lower row, cells were treated with $200 \mu \mathrm{M}$ ddFSK for the reported times. Diagrams are displayed as in Figure 1

Table 1 ddFSK inhibits the respiratory rate $\left(J_{0}\right)$ and reduces the inner membrane electrochemical gradient $\left(\Delta \psi_{\mathrm{m}}\right)$ of isolated mitochondria

\begin{tabular}{|c|c|c|c|}
\hline [ddFSK] & $\stackrel{\Delta \psi_{m}}{(-m \mathbf{v})}$ & $\begin{array}{c}J_{0} \\
\text { (nAtO } / \\
\text { min mg) } \\
\text { Basal }\end{array}$ & $\begin{array}{c}\mathrm{J}_{0} \\
\text { (nAtO } \\
\text { min mg) } \\
\operatorname{Max} / \\
\text { (+FCCP) }\end{array}$ \\
\hline \multicolumn{4}{|c|}{ Substrate: glutamate $(5 \mathrm{mM})$ - malate $(2.5 \mathrm{mM})$} \\
\hline Ctr & 182 & 12.9 & 53.2 \\
\hline $10 \mu \mathrm{M}$ & 182 & 10.9 & 31.5 \\
\hline $50 \mu \mathrm{M}$ & 178 & 10.9 & 23.4 \\
\hline $200 \mu \mathrm{M}$ & 169 & 10.9 & 17.4 \\
\hline \multicolumn{4}{|c|}{ Substrate: succinate $(5 \mathrm{mM})$ with rotenone $(2 \mu \mathrm{M})$} \\
\hline Ctr & 181 & 24.0 & 121 \\
\hline $10 \mu \mathrm{M}$ & 181 & 24.4 & 108 \\
\hline $50 \mu \mathrm{M}$ & 175 & 19.6 & 88.0 \\
\hline $200 \mu \mathrm{M}$ & 159 & 14.1 & 38.7 \\
\hline
\end{tabular}

Experiments were performed as reported in Materials and Methods section. The addition of the protonophoric uncoupler FCCP $(100 \mathrm{nM})$ allowed to measure the maximal respiratory rate (determined as the normalized number of oxygen atoms)
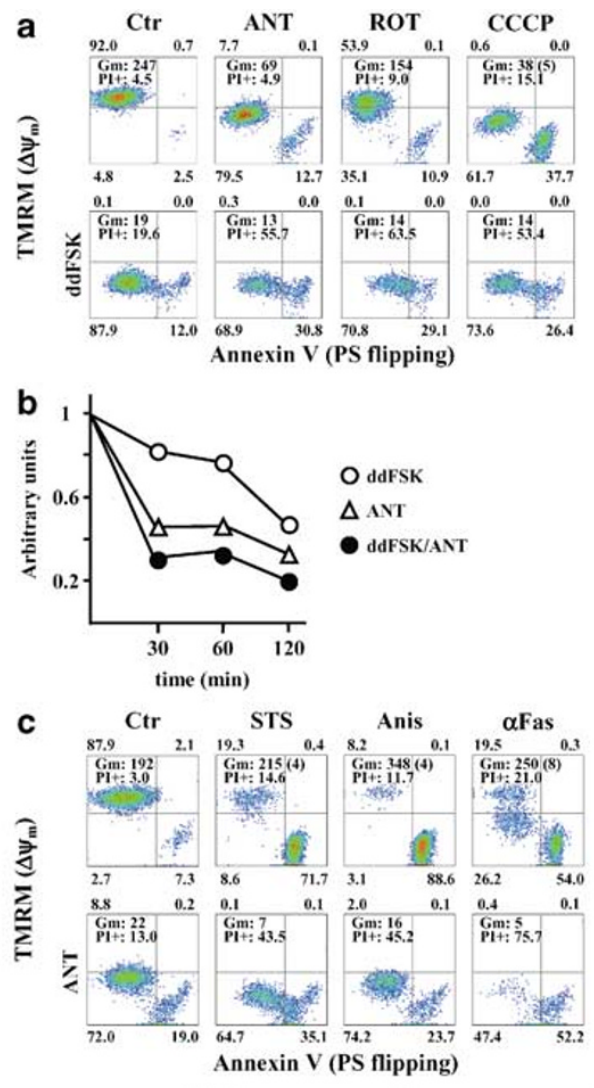

d

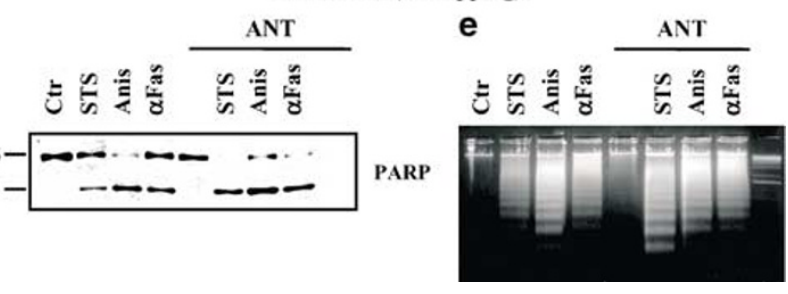

Figure 7 Mitochondrial depolarization and apoptosis. (a) Jurkat cells were exposed for $5 \mathrm{~h}$ to $50 \mu \mathrm{M}$ ANT, $50 \mu \mathrm{M}$ ROT or $50 \mu \mathrm{M}$ CCCP. Where indicated, cells were pretreated for 5 min with ddFSK $(200 \mu \mathrm{M})$. Diagrams are displayed as in Figure 1. (b) Kinetics of mitochondrial depolarization. Jurkat cells were exposed for the indicated times to ddFSK $(200 \mu \mathrm{M})$, ANT $(50 \mu \mathrm{M})$, or to the combination of these compounds. The geometric mean value of the TMRM staining is calculated as in Figure 1, and reported as arbitrary units normalized versus control values. (c-e) Jurkat cells were exposed for $5 \mathrm{~h}$ to $150 \mathrm{ng} / \mathrm{ml}$ STS, $500 \mathrm{ng} / \mathrm{ml}$ Anis, or $150 \mathrm{ng} / \mathrm{ml} \alpha$ Fas. Where indicated, cells were coincubated with $50 \mu \mathrm{M}$ ANT. In (c), the cytofluorimetric analysis and the data presentation are as in Figure 1. In (d), a Western immunoblot assay of the cleavage of PARP is reported; in (e), oligonucleosomal DNA fragmentation is assessed by agarose gel electrophoresis

Figures $6 \mathrm{~b}$ and $8 \mathrm{a}, \mathrm{b})$. The phosphorylation of GSK3, a PKB/ Akt substrate, indicates that the phosphorylation of Ser473 matches the enzyme activity (Figure 10c). To verify whether $\mathrm{PKB} / \mathrm{Akt}$ inhibition could be causative of the energy metabolism changes observed with ddFSK, we infected Jurkat cells with lentiviral vectors containing the constitutive active or dominant-negative form of PKB/Akt. The active form of the enzyme reduced the apoptotic response to intrinsic inducers, whereas the dominant-negative enzyme enhanced it (Figure 10d) and the response to Fas was unchanged (not shown). Nonetheless, PKB/Akt activation or inactivation had no effect on ATP depletion, inhibition of lactate production (Figure 10e), 

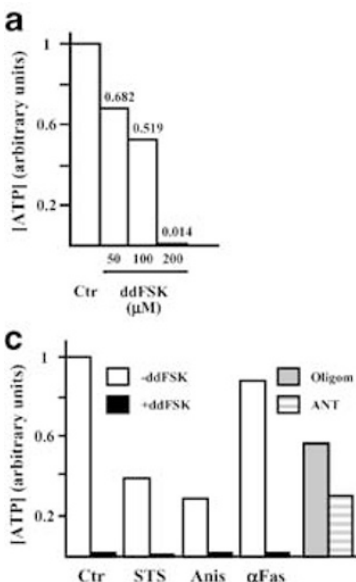

e
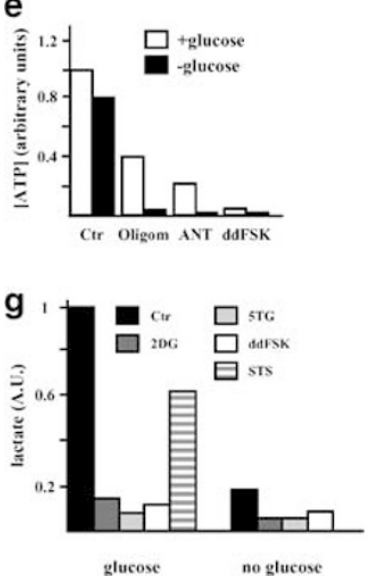

b

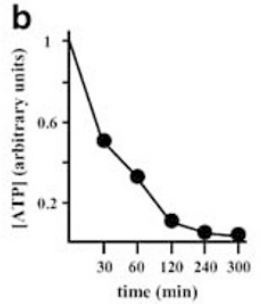

d

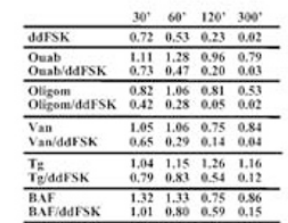

f
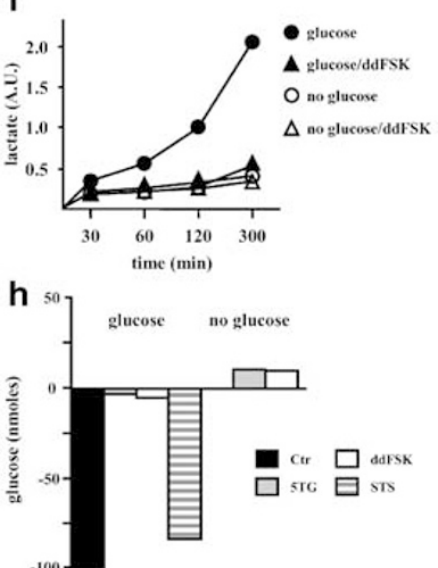

Figure 8 Effect of ddFSK on cell energy metabolism. Dose-response (a, $5 \mathrm{~h}$ exposure) and kinetic analysis (b) of the effect of ddFSK on intracellular ATP concentration in Jurkat cells. In (c), apoptosis was elicited by treating cells for $5 \mathrm{~h}$ with $150 \mathrm{ng} / \mathrm{ml}$ STS, $500 \mathrm{ng} / \mathrm{ml}$ Anis, or $150 \mathrm{ng} / \mathrm{ml} \alpha$ Fas. Where indicated, cells were pretreated for $5 \mathrm{~min}$ with ddFSK $(200 \mu \mathrm{M})$. The $\mathrm{F}_{0} \mathrm{~F}_{1}$ ATPase inhibitor oligomycin (Oligom, $10 \mu \mathrm{M})$ or ANT $(50 \mu \mathrm{M})$ were used to inhibit oxidative phosphorylation. In (d), a kinetic analysis of the effect of several ATPase inhibitors, alone or in association with ddFSK, on intracellular ATP concentration is reported. Ouab: $100 \mu \mathrm{M}$ ouabain; Oligom: $10 \mu \mathrm{M}$ oligomycin; Van: $1 \mathrm{mM}$ vanadate; Tg: $50 \mathrm{nM}$ thapsigargin; BAF: $25 \mathrm{nM}$ bafilomycin $A_{1}$. (e) Effect of glucose depletion on intracellular ATP concentration. Jurkat cells were exposed for $5 \mathrm{~h}$ to $10 \mu \mathrm{M}$ Oligom, $50 \mu \mathrm{M}$ ANT or $200 \mu \mathrm{M}$ ddFSK in normal or glucose-free RPMI medium. Intracellular ATP was quantified by the luciferin/luciferase method. (f, g) Kinetic and $5 \mathrm{~h}$ end point analysis of the effect of $200 \mu \mathrm{M}$ ddFSK on lactate production in normal or glucose-free RPMI medium. In (g), the glycolysis inhibitors 2DG or 5TG (20 mM each) and STS were also tested. (h) Changes of glucose concentration in normal or glucose-free RPMI medium after exposure to ddFSK, 5TG and STS in the same experimental conditions of $(\mathbf{g})$. Lactate and glucose were quantified by spectrophotometric assays. Each experiment was performed in duplicate, and arbitrary units of ATP or lactate concentration were normalized versus control conditions

glucose consumption or mitochondrial depolarization (not shown). We, therefore, conclude that the inhibition of PKB/Akt is a consequence rather than a cause of the profound metabolic alterations mediated by ddFSK.

\section{Discussion}

In the present work, we show that in several cell models the apoptotic process can be switched to necrosis downstream of apoptosome formation in mitochondria-triggered PCD pathways. We demonstrate that cell incubation with the diterpene ddFSK abrogates energy metabolism by affecting both glycolysis and oxidative phosphorylation, and resulting in a massive cell ATP depletion. This energetic catastrophe elicits cell death by a slow necrotic process and interrupts the apoptotic program initiated by intrinsic inducers before the complete activation of the degradation machinery. Due to the lack of energy supply, cells rapidly become unable to sustain the ordered execution of the several subroutines which compose the apoptotic process and are terminated in a necrotic fashion. We therefore reasoned that ddFSK could be a useful tool to study factors which determine the choice between apoptotic and necrotic demise.

Here we have provided a mechanistic basis for this effect of ddFSK. Caspase activation and the processing of a number of caspase targets are all abrogated upon cell exposure to a panel of intrinsic apoptotic stimuli in the presence of ddFSK; yet, caspases are not directly targeted by ddFSK, inasmuch as they can be activated in vitro in the presence of the drug. Nonetheless, cells treated with ddFSK are committed to die irrespective of caspase activation. We asked whether ddFSK could interfere with the death process by affecting the release of mitochondrial proteins active in apoptosis. Strikingly, we found that ddFSK enhances the inner membrane depolarization and the release of apoptogenic molecules from the intermembrane space, and that the apoptosome normally assembles in the presence of ddFSK (Figure 3a).

The complete depletion of intracellular ATP induced by ddFSK explains the lack of apoptosome activation and the block of further apoptotic steps. In fact, the conformational changes of Apaf-1 needed for apoptosome-mediated caspase activation require the binding of dATP/ATP after Apaf-1 interaction with cyt $c$, and caspase activity itself requires ATP hydrolysis. ${ }^{25,26}$ Thus, dATP could reasonably substitute for ATP to allow apoptosome assembly in conditions of energy depletion, but the further steps of caspase activation would be blocked. Since impairment of mitochondrial ATP production can lead to necrosis by itself, ${ }^{27}$ or turn the mitochondriatriggered cell death towards a necrotic mode, blocking late catabolic events, ${ }^{11-13}$ we initially suspected that ATP depletion by ddFSK was caused by mitochondrial dysfunction, but this proved not to be the case. Indeed: (i) in experiments with isolated mitochondria, ddFSK had marginal effects on mitochondrial energy coupling; (ii) rather than causing a dose-dependent effect on mitochondria in situ, ddFSK abruptly caused mitochondrial depolarization only at $200 \mu \mathrm{M}$; (iii) mitochondrial depolarization achieved through block of the respiratory chain or dissipation of the proton gradient through uncoupling was per se an apoptotic stimulus, and it accelerated the apoptosis mediated by other inducers; indeed, ANT, ROT, CCCP or PTP inducers and ddFSK had a synergistic effect, suggesting different mechanisms of action (Figure 7); and (iv) addition of oligomycin did not protect cells from ddFSK-dependent ATP depletion. The latter experiment indicates that in ddFSK-treated cells mitochondria are not utilizing glycolytic ATP in order to maintain the proton electrochemical gradient, an early sign of mitochondrial dysfunction (see Bernardi et al. ${ }^{28}$ for discussion). Likewise, ATP depletion was not caused by increased activity of other 


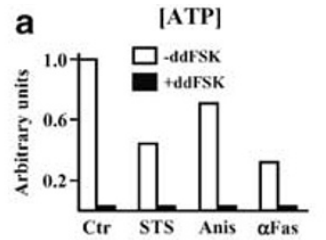

b DEVDase activity
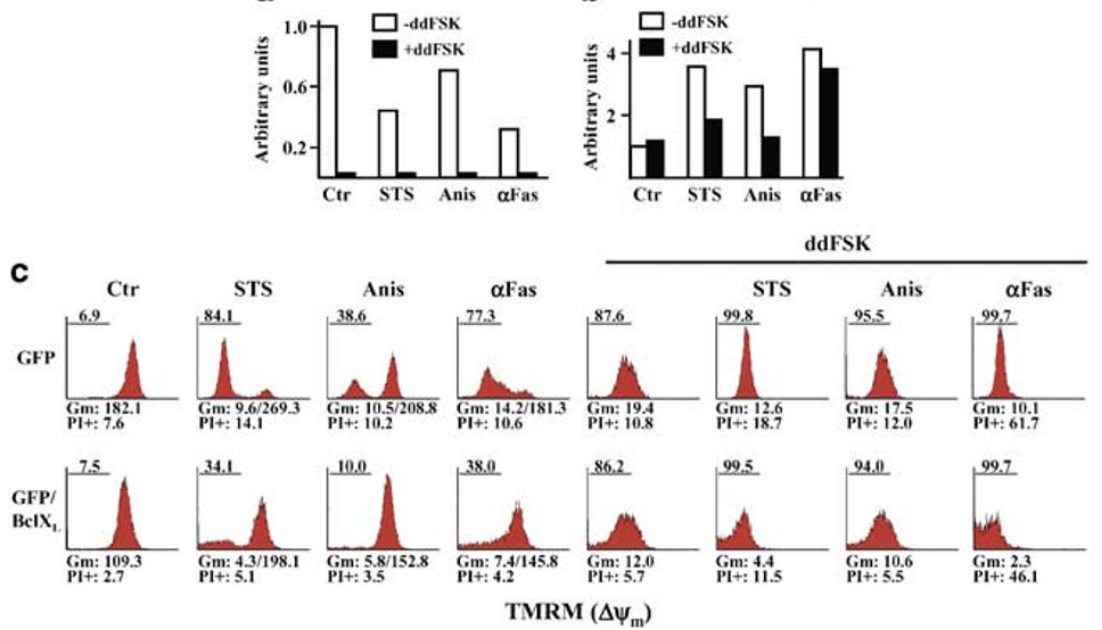

Figure $9 \mathrm{BCl}-\mathrm{X}_{\mathrm{L}}$ overexpression neither inhibits ATP depletion nor mitochondrial depolarization mediated by ddFSK. (a) Measurement of intracellular ATP concentration on GFP/Bcl-X Jurkat cells treated for $5 \mathrm{~h}$ with $150 \mathrm{ng} / \mathrm{ml} \mathrm{STS}, 500 \mathrm{ng} / \mathrm{ml}$ Anis, or $150 \mathrm{ng} / \mathrm{ml} \alpha$ Fas. Where indicated, cells were pretreated for $5 \mathrm{~min}$ with ddFSK $(200 \mu \mathrm{M})$. Experiments were performed as in Figure 8. (b) Caspase 3/7 activity was measured on GFP/Bcl-X Jurkat cells as DEVDase activity (see Figure 3 ). Cells were treated as in (a). (c) Loss of $\Delta \psi_{\mathrm{m}}$ was assessed on GFP and on GFP/Bcl-X $\mathrm{L}_{\mathrm{L}}$ Jurkat cells as cytofluorimetric measurement of the TMRM signal. The bar over each plot indicates the percentage of cells displaying depolarized mitochondria (reduced TMRM signal), whereas the geometric mean (Gm) of each TMRM peak is at the bottom of the diagrams (where two peaks are present, both $\mathrm{Gm}$ values are reported). The percentage of $\mathrm{PI}+$, that is, dead cells, is reported for each condition

cellular ATPases, as judged by the lack of effects of selective inhibitors.

Remarkably, lactate production, that is, glycolytic activity, is abrogated in ddFSK-treated cells. As this matches the depletion of ATP and the impairment of mitochondrial energy production, one could postulate that ddFSK affects an upstream common step in the energy metabolism cascades. We excluded a direct inhibition of either hexokinase or lactate dehydrogenase activity. A possible candidate is the facilitated transport of glucose across the plasma membrane, and the observation of a lack of glucose consumption from the medium of ddFSK-treated cells further strengthens this hypothesis. However, the finding that glucose is released by incubation with ddFSK or glycolysis inhibitors in a glucosefree medium (Figure 10h) indicates that transport is active, and that ddFSK could selectively block glucose uptake. Glucose depletion will affect both the production of ATP by glycolysis and the supply of substrates to mitochondria. This would cause mitochondrial depolarization, trigger the opening of the voltage-dependent permeability transition pore, ${ }^{29}$ and result in assembly of the apoptosome.

The inhibition of postmitochondrial steps by energy depletion in Fas-mediated cell death causes a switch towards necrosis in type II cells, where caspase activation needs mitochondria triggering, but has no effect on the signaling cascade in type I cells, where caspase activation is directly associated with receptor engagement. ${ }^{11-13}$ We observe that the mode of Fas-dependent cell death is unaffected by ddFSK, according to a type I cell model, with ddFSK acting downstream of the ATP/apoptosome-independent caspase activation step.

A link between cell energy metabolism and apoptosis can be provided by the $\mathrm{Bcl}-2$-like protein $\mathrm{Bcl}-\mathrm{X}_{\mathrm{L}}$ and by the serine/ threonine kinase $\mathrm{PKB} / \mathrm{Akt}$. $\mathrm{Bcl}-\mathrm{X}_{\mathrm{L}}$ was proposed to prevent apoptosis by facilitating mitochondrial respiration in conditions of poor metabolite supply. ${ }^{15-17}$ However, we could not measure any inhibition of ddFSK-mediated ATP depletion or mitochondrial depolarization in Bcl- $\mathrm{X}_{\mathrm{L}}$ overexpressing cells, even if the effect of the tested apoptosis inducers was largely reduced. Activation of PKB/Akt stimulates glycolysis and supply of substrates to mitochondria. In fact, it enhances glucose uptake by stimulating the expression of the plasma membrane glucose transporter Glut-1, ${ }^{18}$ and it mediates the activation of 6-phosphofructo-2-kinase ${ }^{19}$ and hexokinase. ${ }^{20}$ Thus, PKB/Akt activation may favor cell survival, ${ }^{21,22}$ or alternatively it may support execution of the final apoptotic steps in committed cells. We have observed that PKB/Akt activity is inhibited by ddFSK, but a constitutive active form of the enzyme cannot counteract any of the inhibitory effects of the drug on cell energy metabolism. Indeed, these observations indicate that, even though $\mathrm{Bcl}-\mathrm{X}_{\mathrm{L}}$ and $\mathrm{PKB} / \mathrm{Akt}$ at least partially influence the apoptotic response of the cells, they are not the elements coupling energy metabolism and apoptosis execution affected by ddFSK, nor they do control any such elements.

ddFSK is commonly used as an inactive analogue of the adenylyl cyclase activator forskolin and as an inhibitor of some $\mathrm{Cl}^{-}$and $\mathrm{K}^{+}$currents and of the permeability to organic osmolytes. ${ }^{30-32}$ We had observed that ddFSK was able to block late apoptotic events. ${ }^{24}$ Here we explain those data through the definition of a novel activity of ddFSK as a cell energy metabolism blocker. In summary, our results indicate that the process of programmed cell death displays complex regulatory mechanisms tightly linked to energy metabolism. The tuning of the mode of cell demise depends on cell energy levels: under a certain threshold of energy availability, cells undergo necrosis, even though apoptosis per se does not require adequate ATP levels provided that the caspase cascade is triggered. In the present work, we show that a single treatment abrogates the cell capability to produce ATP both by glycolysis and by oxidative phosphorylation, and that concomitant inhibition of the two pathways is needed to switch 
a
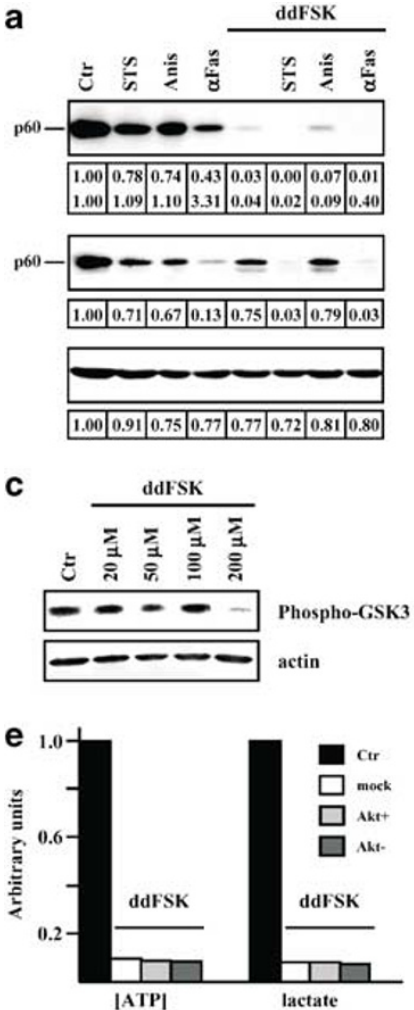
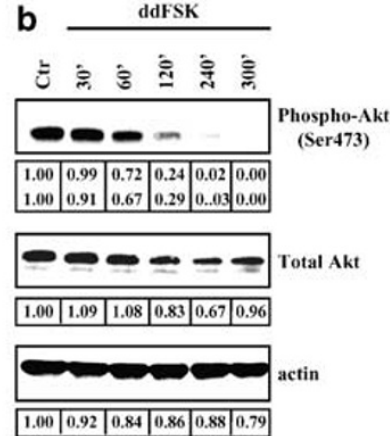

d

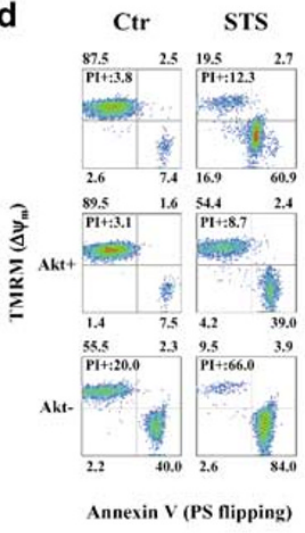

Figure $10 \mathrm{PKB} / \mathrm{Akt}$ activity is inhibited by ddFSK as a result of cell metabolic changes. (a, b) Western immunoblot detecting the phosphorylation of the Ser473 residue of PKB/Akt. Each blot was then reassessed for total PKB/Akt and for actin. A densitometric analysis was performed to measure the relative band intensity: the tables under each blot report values normalized versus contro conditions, versus actin (in the case of total Akt) or versus total Akt (lower row of phospho-Akt). In (a), Jurkat cells were incubated in the same conditions of Figure 1. In (b), cells were treated for the reported times with $200 \mu \mathrm{M}$ ddFSK. (c) Analysis of the phosphorylation state of the PKB/Akt substrate GSK3 after a $5 \mathrm{~h}$ cell treatment with the reported concentrations of ddFSK. (d, e) Effect of the expression of the constitutive active or dominant-negative form of PKB/Akt (reported as Akt + and Akt-, respectively) on apoptosis induction with STS, on intracellular ATP concentration and on lactate production. In (d), cells were treated and analyzed as in Figure 1; in (e), as in Figure 8

the mode of cell death from apoptosis to necrosis when cells are committed to die by intrinsic stimuli. A better understanding of the interactions between the control of energy homeostasis and the regulation of cell demise is needed, given the physiological relevance of the modulation of programmed cell death. ddFSK could be a useful tool to unravel these intricate causal relationships, and it could pave the way for a new class of PCD or energy metabolism regulators.

\section{Materials and Methods}

\section{Chemicals and antibodies}

The caspase inhibitor Z.VAD-fluoro-methyl-ketone (Z.VAD-fmk) was from Bachem (Subendorf, Switzerland), thapsigargin from Alexis Biochemicals (Lausanne, Switzerland), FITC-conjugated Annexin-V from Boehringer Mannheim (Indianapolis, IN, USA), DAPI and TMRM from Molecular Probes (Eugene, OR, USA); all other chemicals were from Sigma (St. Louis, MO, USA). $\mathrm{CH}-11$ anti-Fas monoclonal antibody was from Upstate

Biotechnology (Lake Placid, NY, USA), anti-PARP, anti-cyt $c$ and anticaspase-7 monoclonal antibodies, and anti-caspase-8 and anti-Apaf-1 polyclonal antibodies were from PharMingen (San Diego, CA, USA), anti$\mathrm{BCl}-\mathrm{X}_{\mathrm{L}}$ polyclonal antibody and anti-caspase-3 monoclonal antibodies were from Transduction Laboratories (Lexington, KY, USA); anti-actin and anti-caspase-9 polyclonal antibodies were from Santa Cruz Biotechnology (Santa Cruz, CA, USA); anti-cytochrome oxidase subunit VIc monoclonal antibody was from Molecular Probes; anti-lamin B monoclonal antibody was from Oncogene Research (Boston, MA, USA); anti-AIF polyclonal antibody was from Exalpha Biologicals (Boston, MA, USA); anti-SMAC/ Diablo polyclonal antibody was from Medical and Biological Laboratories (Nagoya, Japan); anti-phospho-Akt (Ser473) and anti-total Akt polyclonal antibodies were from Cell Signaling Technology (Beverly, MA, USA).

\section{Cell culture, apoptosis induction and expression of $\mathrm{Bcl}-\mathrm{X}_{\mathrm{L}}$ and PKB/Akt constructs}

Human T-leukemia Jurkat cells were grown in RPMI-1640 culture medium supplemented with $5 \%$ fetal bovine serum (Gibco BRL, MD, USA) and $2 \mathrm{mM}$ L-glutamine. Unless otherwise stated, in order to trigger apoptosis, cells were incubated for $5 \mathrm{~h}$ with the different agonists in multiwell tissue culture plates at a seeding density of $10^{6} \mathrm{cell} / \mathrm{s} / \mathrm{ml}$. Caspase inhibitors were preincubated for $30 \mathrm{~min}$ before addition of the proapoptotic compounds. Control experiments were performed to exclude for nonspecific effects of the solvent (DMSO) on apoptosis induction. In order to overexpress Bcl$X_{L}$, Jurkat cells were stably cotransfected by lipofection (Lipofectin ${ }^{\circledR}$ reagent, Gibco $B R L$ ) with a pEGFP-N1 vector (Clontech, Palo Alto, CA, USA) and with a pUC-CAGGS vector in which the full-length $B c l-X_{L}$ had been inserted into the $E c o R I$ cloning site. Cells were kept in selection with $1 \mathrm{mg} / \mathrm{ml} \mathrm{G418;} \mathrm{green} \mathrm{cells} \mathrm{were} \mathrm{then} \mathrm{sorted} \mathrm{on} \mathrm{a} \mathrm{Beckman} \mathrm{Coulter} \mathrm{Epics}$ Altra flow cytometer and Bcl- $X_{L}$ level was assessed by Western immunoblot analysis. To overexpress wild-type or mutated Akt, Jurkat cells were infected with the lentiviral vector pRRLsin.PPT.hCMV, ${ }^{33}$ in which the wild-type or mutated HA-Akt were cloned as BamHI/Sall fragments from the plasmid pCMV-HA-Akt. The mutated forms of HA-Akt were a constitutively active enzyme produced by inserting the double mutation T308D/S473D and a dominant-negative construct obtained by T308A/S473A mutations. pRRLsin.PPT.hCMV-HA-Akt transfer vectors were used to produce lentiviruses by transient transfection of 293T cells together with the VSV-G and pCMV $\triangle$ R8.93 plasmids. Viral p24 concentration was determined by HIV-1 p24 Core profile ELISA (NEN Life Science Products, Boston, MA, USA). Transduction experiments were performed by adding a 1:10 dilution of the virus-containing 293T supernatant onto $10^{5}$ cells in the presence of Polybrene. Transduced cells were checked by Western blot with anti-HA antibodies for expression of the recombinant protein.

\section{Flow cytometry analysis}

Several apoptotic parameters were simultaneously assessed on Jurkat cells by FACS analysis, as described. ${ }^{23}$ Briefly, after induction of apoptosis, $5 \times 10^{5}$ cells were resuspended in HEPES buffer $(10 \mathrm{mM}$ HEPES, $150 \mathrm{mM} \mathrm{NaCl}, 5 \mathrm{mM} \mathrm{CaCl}_{2}$ ). Cells were then incubated for $15 \mathrm{~min}$ at $37^{\circ} \mathrm{C}$ in FITC-conjugated Annexin-V, tetramethylrhodamine methyl ester (TMRM, $200 \mathrm{nM}$ ) and propidium iodide (PI; $1 \mu \mathrm{g} / \mathrm{ml}$ ), to detect phosphatidylserine exposure on the cell surface, mitochondrial depolarization and loss of plasma membrane integrity, respectively. Dose-response experiments were performed in order to exclude the quenching effects due to high concentration storage of TMRM into the mitochondria. 
Incubations in a high $\mathrm{K}^{+}$medium were performed in order to exclude a major contribution of the plasma membrane potential to the observed changes of TMRM fluorescence. Samples were analyzed on a FACSCalibur flow cytometer (Becton Dickinson). Data acquisition was performed using the CellQuest software and data analysis with the WinMDI software. FITC-Annexin V (FL1), TMRM (FL2) and PI (FL3) fluorescent signals were shown as density plot diagrams. Data are shown as arbitrary units of fluorescence on a logarithmic scale, whereas light scatter parameters are indicated on a linear scale. A quadrant was set on the diagrams experiment-by-experiment, and it was kept constant in all the conditions of each experiment in order to point out the different cell populations. To quantify the degree of mitochondrial depolarization, the geometric mean $(\mathrm{Gm})$ of the TMRM signal was calculated on the histogram window of WinMDI after discriminating apoptotic and nonapoptotic subpopulations with a logical gate tool.

\section{Cell fractionation and Western immunoblot analysis}

Cytosolic extracts were prepared by lysing Jurkat cells at $4^{\circ} \mathrm{C}$ in $135 \mathrm{mM}$ $\mathrm{NaCl}, 20 \mathrm{mM}$ Tris/ $\mathrm{HCl}$, pH 7.5, $1 \mathrm{mM} \mathrm{CaCl}_{2}, 1 \% \mathrm{NP} 40$, with phosphatase and protease inhibitors ( $1 \mathrm{mM}$ vanadate, $1 \mu \mathrm{g} / \mathrm{ml}$ leupeptine, $1 \mu \mathrm{M}$ pepstatine, $1 \mathrm{mM}$ PMSF, $100 \mu \mathrm{g} / \mathrm{ml}$ soybean trypsin inhibitor). For the separation of subcellular cytosolic and organelle/membrane fractions, $10^{7}$ cells were washed in PBS and resuspended in 50 mM PIPES, pH 7.0, $50 \mathrm{mM} \mathrm{KCl}, 5 \mathrm{mM} \mathrm{MgCl}_{2}, 5 \mathrm{mM}$ EGTA, with phosphatase and protease inhibitors as above. Cells were then lysed by mechanical disruption with a pestle and centrifuged twice at $14000 \times g$ and at $4^{\circ} \mathrm{C}$. The resulting supernatant was assayed for lactate dehydrogenase with the Sigma kit, and experiments were only deemed valid if $95 \%$ of the total LDH activity was in the soluble (cytosolic) fraction. The pellet, which contained membranes and organelles, was further resuspended in the lysis buffer. Lysates were then loaded on SDS-polyacrylamide gels and proteins were blotted onto Hybond-C Extra membranes (Amersham, Little Chalfont, UK) following standard methods. Antibodies were incubated overnight at $4^{\circ} \mathrm{C}$, and horseradish peroxidase-conjugated secondary antibodies were added for $1 \mathrm{~h}$. Proteins were visualized by enhanced chemiluminescence (Amersham).

\section{Immunofluorescence analysis}

Cells incubated with the different apoptotic agents were washed in PBS, fixed in $2 \%$ paraformaldehyde and centrifuged at $800 \times g$ for 5 min onto microscope slides. For the staining with antibodies, cells were then incubated for $3 \mathrm{~h}$ at $4^{\circ} \mathrm{C}$ and in a wet and dark chamber with the primary antibodies at the concentration of $0.2 \mu \mathrm{g} / \mathrm{ml}$, then washed and incubated for $30 \mathrm{~min}$ in the same conditions with the secondary antibody. For the DAPI staining, cells were instead incubated for $5 \mathrm{~min}$ at room temperature with $300 \mathrm{nM}$ DAPI. Samples were observed on a Leica DM-IRB fluorescence microscope equipped with a Hamamatsu C4742-95 digital camera, and images were stored with the use of the Image ProPlus software.

\section{Nuclear changes assays}

DNA fragmentation was analyzed by electrophoresis on agarose gel and by using the cytofluorimetric TdT-mediated dUTP-X nick end labeling (TUNEL) technique. In the former case, after induction of apoptosis, $3 \times 10^{6}$ cells were washed in PBS and lysed in a buffer containing $10 \mathrm{mM}$
Tris, $1 \mathrm{mM}$ EDTA and $0.2 \%$ Triton $\mathrm{X}-100, \mathrm{pH}$ 8.0. Samples were then incubated in $100 \mu \mathrm{g} / \mathrm{ml} \mathrm{RNase} \mathrm{A}\left(30 \mathrm{~min}, 37^{\circ} \mathrm{C}\right.$ ) and $100 \mu \mathrm{g} / \mathrm{ml}$ proteinase $\mathrm{K}\left(10 \mathrm{~min}, 56^{\circ} \mathrm{C}\right)$. DNAs were precipitated in $0.5 \mathrm{M} \mathrm{NaCl}$-isopropanol, washed in $70 \%$ ethanol and loaded on a $1.5 \%$ agarose gel. To assess nucleosomal DNA fragmentation in vitro, cells treated with the different apoptotic inducers were lysed as above, and $450 \mu \mathrm{g}$ of proteins were then incubated for $2 \mathrm{~h}$ at $37^{\circ} \mathrm{C}$ in the presence of $2 \mu \mathrm{g}$ of high molecular weight calf thymus DNA (Boehringer Mannheim, Indianapolis, ID). DNAs were then processed as above. The TUNEL technique was applied on $10^{6}$ cells by use of the in situ cell death detection kit (Boehringer Mannheim), following the manufacturer's instructions. To measure loss of DNA, cells were incubated for $1 \mathrm{~h}$ at room temperature in a buffer containing $0.5 \mathrm{mg} /$ $\mathrm{ml}$ RNase, $0.1 \%$ (w/v) Nonidet P-40 and PI $(50 \mu \mathrm{g} / \mathrm{ml}$; DNAcon3 kit, Consul $^{\text {TS }}$, Torino, Italy). Apoptotic cells exhibit sub-G 1 PI incorporation (hypodiploid cells), whereas necrotic cells do not display loss of DNA within the experimental time period analyzed.

\section{Colorimetric and in vitro caspase activity measurements}

Caspase activity was measured as cleavage of the chromophoreconjugated substrates of caspase-3/7 (DEVD-pNA; DEVDase activity), of caspase-9 (LEHD-pNA; LEHDase activity) or of caspase-8 (IETD-pNA, IETDase activity) by using the ApoAlert ${ }^{\mathbb{R}}$ caspase-3 assay kit (Clontech, Palo Alto, CA, USA) or the caspase-9/caspase-8 colorimetric kits (R\&D Systems, Minneapolis, MN, USA) following the manufacturer's instructions. Each experiment was performed in duplicate, and protease activity was assessed by a colorimetric assay at $405 \mathrm{~nm}$ on an Elx 800 microplate absorbance reader (Bio-Tek Instruments, Winooski, VT, USA). Data are presented as arbitrary units of absorbance normalized versus control conditions. In order to measure the in vitro caspase activity, Jurkat cells were lysed in $20 \mathrm{mM}$ HEPES/ $\mathrm{NaOH}$ (or $20 \mathrm{mM} \mathrm{HEPES} / \mathrm{KOH}$ ), $10 \mathrm{mM}$ $\mathrm{NaCl}$ (or $10 \mathrm{mM} \mathrm{KCl}$ ), $1.5 \mathrm{mM} \mathrm{MgCl}_{2}$ and $1 \mathrm{mM}$ EDTA by mechanical disruption with a pestle, and $350 \mu \mathrm{g}$ of proteins were then incubated for $2 \mathrm{~h}$ at $37^{\circ} \mathrm{C}$ with $1 \mathrm{mM} \mathrm{dATP}, 1 \mathrm{mM}$ dithiothreitol and $10 \mu \mathrm{M}$ cyt $c$ (Sigma) to activate the apoptosome. Samples were then loaded on SDSpolyacrylamide gels and Western blots were performed as above.

\section{Mitochondrial respiratory rate assay}

Mitochondria were isolated from the livers of female Albino Wistar rats weighing about $300 \mathrm{~g}$ following standard procedures. ${ }^{34}$ Experiments were performed in a buffer composed of $250 \mathrm{mM}$ sucrose, $10 \mathrm{mM}$ Tris-Mops $(\mathrm{pH}$ 7.4), $5 \mathrm{mM}$ glutamate-Tris, $2.5 \mathrm{mM}$ malate-Tris, $1 \mathrm{mM}$ Tris-phosphate, $20 \mu \mathrm{M} \mathrm{EGTA}$, and mitochondrial membrane potential was determined with the probe rhodamine 123 (Molecular Probes) as described. ${ }^{35}$ The respiratory rate was assessed with a Clark-type oxygen electrode in a closed 2-ml chamber equipped with magnetic stirring and thermostatic control.

\section{Intracellular ATP determination and lactate and glucose measurements}

Intracellular ATP was quantified by the luciferin/luciferase method using the Molecular Probes ATP determination kit, following the manufacturer's instructions. Briefly, after apoptosis was induced as reported above, $10 \mu \mathrm{g}$ of cell lysates were analyzed in a Lumat-LB-9507 luminometer (Berthold, Australia) in a final volume of $20 \mu \mathrm{l}$. Each experiment was performed in duplicate, and values were normalized versus control conditions. Lactate 
and glucose were measured in sample supernatants by using the Sigma kits 826-UV and 115, respectively, following manufacturer's instructions.

\section{Acknowledgements}

This work was supported by grants of the Associazione Italiana Ricerca Cancro (AIRC) to both groups involved. We are indebted to Professor Paolo M. Comoglio for continuous support, to Dr. Lorenza D'Alessandro and Dr. Massimo Geuna for helpful discussions, to Professor Yoshihide Tsujimoto and to Professor Brian Hemmings for providing the $B c l-X_{L}$ and the PKB/Akt plasmids, respectively. We thank Raffaella Albano, Laura Palmas and Solange Tienga for technical assistance.

\section{References}

1. Strasser A, O'Connor L and Dixit VM (2000) Apoptosis signaling. Annu. Rev. Biochem. 69: 217-245

2. Zornig M, Hueber A, Baum W and Evan G (2001) Apoptosis regulators and their role in tumorigenesis. Biochim. Biophys. Acta 1551: F1-F37

3. Budihardjo I, Oliver H, Lutter M, Luo X and Wang X (1999) Biochemical pathways of caspase activation during apoptosis. Annu. Rev. Cell Dev. Biol. 15: 269-290

4. Gross A, McDonnell JM and Korsmeyer SJ (1999) BCL-2 family members and the mitochondria in apoptosis. Genes Dev. 13: 1899-1911

5. Adrain C and Martin SJ (2001) The mitochondrial apoptosome: a killer unleashed by the cytochrome seas. Trends Biochem. Sci. 26: 390-397

6. Wallach D, Varfolomeev EE, Malinin NL, Goltsev YV, Kovalenko AV and Boldin MP (1999) Tumor necrosis factor receptor and Fas signaling mechanisms. Annu. Rev. Immunol. 17: 331-367

7. Leist $M$ and Jaattela $M$ (2001) Four deaths and a funeral: from caspases to alternative mechanisms. Nat. Rev. Mol. Cell Biol. 2: 589-598

8. Nicotera P, Leist M and Manzo L (1999) Neuronal cell death: a demise with different shapes. Trends Pharmacol. Sci. 20: 46-51

9. Cohen GM (1997) Caspases: the executioners of apoptosis. Biochem. J. 326: 1-16

10. Leist M, Single B, Naumann H, Fava E, Simon B, Kuhnle $S$ and Nicotera $P$ (1999) Inhibition of mitochondrial ATP generation by nitric oxide switches apoptosis to necrosis. Exp. Cell Res. 249: 396-403

11. Leist M, Single B, Castoldi AF, Kuhnle S and Nicotera P (1997) Intracellular adenosine triphosphate (ATP) concentration: a switch in the decision between apoptosis and necrosis. J. Exp. Med. 185: 1481-1486

12. Eguchi Y, Srinivasan A, Tomaselli KJ, Shimizu S and Tsujimoto Y (1999) ATP-dependent steps in apoptotic signal transduction. Cancer Res. 59: 2174-2181

13. Ferrari D, Stepczynska A, Los M, Wesselborg S and Schulze-Osthoff K (1998) Differential regulation and ATP requirement for caspase-8 and caspase-3 activation during CD95- and anticancer drug-induced apoptosis. J. Exp. Med. 188: 979-984

14. Latta M, Kunstle G, Leist M and Wendel A (2000) Metabolic depletion of ATP by fructose inversely controls CD95- and tumor necrosis factor receptor 1 . mediated hepatic apoptosis. J. Exp. Med. 191: 1975-1985

15. Gottlieb E, Vander Heiden MG and Thompson CB (2000) Bcl-x(L) prevents the initial decrease in mitochondrial membrane potential and subsequent reactive oxygen species production during tumor necrosis factor alpha-induced apoptosis. Mol. Cell. Biol. 20: 5680-5689
16. McClintock DS, Santore MT, Lee VY, Brunelle J, Budinger GR, Zong WX, Thompson CB, Hay N and Chandel NS (2002) Bcl-2 family members and functional electron transport chain regulate oxygen deprivation-induced cell death. Mol. Cell. Biol. 22: 94-104

17. Vander Heiden MG, Chandel NS, Schumacker PT and Thompson CB (1999) $\mathrm{Bcl}-\mathrm{xL}$ prevents cell death following growth factor withdrawal by facilitating mitochondrial ATP/ADP exchange. Mol. Cell 3: 159-167

18. Barthel A, Okino ST, Liao J, Nakatani K, Li J, Whitlock Jr JP and Roth RA (1999) Regulation of GLUT1 gene transcription by the serine/threonine kinase Akt1. J. Biol. Chem. 274: 20281-20286

19. Deprez J, Vertommen D, Alessi DR, Hue L and Rider MH (1997) Phosphorylation and activation of heart 6-phosphofructo-2-kinase by protein kinase $B$ and other protein kinases of the insulin signaling cascades. J. Biol. Chem. 272: 17269-17275

20. Gottlob K, Majewski N, Kennedy S, Kandel E, Robey RB and Hay N (2001) Inhibition of early apoptotic events by Akt/PKB is dependent on the first committed step of glycolysis and mitochondrial hexokinase. Genes Dev. 15: $1406-1418$

21. Kennedy SG, Kandel ES, Cross TK and Hay N (1999) Akt/Protein kinase B inhibits cell death by preventing the release of cytochrome $c$ from mitochondria. Mol. Cell. Biol. 19: 5800-5810

22. Plas DR, Talapatra S, Edinger AL, Rathmell JC and Thompson CB (2001) Akt and $\mathrm{BCl}-\mathrm{xL}$ promote growth factor-independent survival through distinct effects on mitochondrial physiology. J. Biol. Chem. 276: 12041-12048

23. Rasola A and Geuna M (2001) A flow cytometry assay simultaneously detects independent apoptotic parameters. Cytometry 45: 151-157

24. Rasola A, Farahi Far D, Hofman P and Rossi B (1999) Lack of internucleosomal DNA fragmentation is related to $\mathrm{Cl}(-)$ efflux impairment in hematopoietic cell apoptosis. FASEB J. 13: 1711-1723

25. Acehan D, Jiang X, Morgan DG, Heuser JE, Wang X and Akey CW (2002) Three-dimensional structure of the apoptosome: implications for assembly, procaspase-9 binding, and activation. Mol. Cell 9: 423-432

26. Jiang $X$ and Wang $X(2000)$ Cytochrome $c$ promotes caspase- 9 activation by inducing nucleotide binding to Apaf-1. J. Biol. Chem. 275: 31199-31203

27. Almeida A and Bolanos JP (2001) A transient inhibition of mitochondrial ATP synthesis by nitric oxide synthase activation triggered apoptosis in primary cortical neurons. J. Neurochem. 77: 676-690

28. Bernardi P, Scorrano L, Colonna R, Petronilli V and Di Lisa F (1999) Mitochondria and cell death. Mechanistic aspects and methodological issues. Eur. J. Biochem. 264: 687-701

29. Bernardi $P$ (1999) Mitochondrial transport of cations: channels, exchangers, and permeability transition. Physiol. Rev. 79: 1127-1155

30. Galietta LJ, Rasola A, Barone V, Gruenert DC and Romeo G (1991) A forskolin and verapamil sensitive $\mathrm{K}^{+}$current in human tracheal cells. Biochem. Biophys. Res. Commun. 179: 1155-1160

31. Moran J, Miranda D, Pena-Segura C and Pasantes-Morales H (1997) Volume regulation in $\mathrm{NIH} / 3 \mathrm{~T} 3$ cells not expressing P-glycoprotein. II. Chloride and amino acid fluxes. Am. J. Physiol. 272: C1804-C1809

32. Rasola A, Galietta LJ, Gruenert DC and Romeo G (1994) Volume-sensitive chloride currents in four epithelial cell lines are not directly correlated to the expression of the MDR-1 gene. J. Biol. Chem. 269: 1432-1436

33. Follenzi A, Ailles LE, Bakovic S, Geuna M and Naldini L (2000) Gene transfer by lentiviral vectors is limited by nuclear translocation and rescued by HIV-1 pol sequences. Nat. Genet. 25: 217-222

34. Costantini P, Petronilli V, Colonna R and Bernardi P (1995) On the effects of paraquat on isolated mitochondria. Evidence that paraquat causes opening of the cyclosporin A-sensitive permeability transition pore synergistically with nitric oxide. Toxicology 99: 77-88

35. Emaus RK, Grunwald R and Lemasters JJ (1986) Rhodamine 123 as a probe of transmembrane potential in isolated rat-liver mitochondria: spectral and metabolic properties. Biochim. Biophys. Acta 850: 436-448 